\title{
Intramuscular loading dose of quinine for falciparum malaria: pharmacokinetics and toxicity
}

\author{
YUPAPORN WATTANAGOON, R E PHILLIPS, D A WARRELL, KAMOLRAT SILAMUT, \\ SORNCHAI LOOAREESUWAN， BUSSURIN NAGACHINTA，D J BACK
}

\begin{abstract}
In a study of intramuscular injection of quinine eight adults with moderately severe falciparum malaria resistant to chloroquine were treated with quinine dihydrochloride, being given a loading dose of $20 \mathrm{mg}$ salt $(16.7 \mathrm{mg}$ base $) / \mathrm{kg}$ followed by three or four eight hourly maintenance doses of $10 \mathrm{mg}$ salt $(8.3 \mathrm{mg}$ base $) / \mathrm{kg}$ injected into the anterior thigh. All patients responded to treatment. Fever and parasite clearance times (mean (SD) 60 (23) h and 53 (22) h respectively) were comparable with those obtained with intravenous quinine. The mean peak plasma quinine concentration of $11.0 \mathrm{mg} / 1(34.4 \mathrm{mmol} / \mathrm{l})$ was reached a median of five hours after administration of the loading dose. In all patients plasma quinine concentrations exceeded the high minimum inhibitory concentration for Plasmodium falciparum malaria prevalent in Thailand within four hours of the start of treatment but did not cause toxicity other than mild cinchonism.

When intravenous infusion is not possible an intramuscular quinine loading dose is an effective means of starting treatment in patients with moderately severe falciparum malaria who cannot swallow tablets.
\end{abstract}

\section{Introduction}

Quinine is now the only drug recommended by the World Health Organisation for the treatment of severe malaria world wide. 'This is because parenteral chloroquine is considered to be dangerous, especially when given as an intramuscular injection to children. ${ }^{2}$ Quinine is also a potentially toxic drug, so is it a safe substitute for chloroquine, particularly in endemic areas where paramedical workers are responsible for initiating treatment?

Controlled intravenous infusions of quinine are safe, ${ }^{3}$ but this method of administration is out of the question in much of the rural tropics where most patients must be treated. Intravenous injections carry an unacceptable risk: the transient but high quinine concentrations that result may cause serious cardiovascular poisoning. ${ }^{4}$ Intramuscular quinine has been in use for more than 100 years, ${ }^{5}$ but opinions on the safety and efficacy of this method differ so widely that in the absence of more information it could not be advocated for the treatment of severe malaria. ${ }^{6-11}$ Yet if it were shown to be effective and safe treatment regimens could be simplified and delays in starting treatment reduced. It is the only parenteral route of administration that can be used by primary health workers.

Because of the uncertain safety and efficacy of intramuscular

\footnotetext{
Hospital for Tropical Diseases, Faculty of Tropical Medicine, Mahidol University, Bangkok 10400, Thailand

YUPAPORN WATTANAGOON, MB, lecturer

R E PHILLIPS, FRACP, Wellcome lecturer

D A WARRELL, DM, FRCP, consultant

KAMOLRAT SILAMUT, MSC, medical laboratory technologist

SORNCHAI LOOAREESUWAN, MD, DTM\&H, associate professor

Paholpolpayuhasena Hospital, Kanchanaburi, Thailand

BUSSURIN NAGACHINTA, MD, physician

Department of Pharmacology and Therapeutics, University of Liverpool,
Liverpool
D J BACK, PHD, senior lecturer
Correspondence and requests for reprints to: Dr Warrell.
}

quinine and the increasing need to debate its use we studied this route for the treatment of moderately severe falciparum malaria resistant to chloroquine.

\section{Patients and methods}

Patients admitted to Paholpolpayuhasena Hospital, Kanchanaburi, Thailand, were selected for this study if they were older than 15 , had asexual forms of Plasmodium falciparum in peripheral blood smears, and were so ill as to be unable to swallow tablets. Patients were excluded if they were over 65; were pregnant; were severely ill with cerebral, renal, or other complications; had mixed infections; or gave a history of recent quinine treatment. All patients gave informed consent to investigation, treatment, and follow up. The study was approved by ethical committees of the Faculty of Tropical Medicine, Mahidol University, Bangkok, and of the Ministry of Health, Government of Thailand.

On admission patients were weighed and treatment started immediately. Baseline investigations included measurement of full blood count; blood urea nitrogen; serum creatinine, bilirubin, aminoaspartate transferase, and albumin; and plasma quinine. Urine was tested for sulphonamides (lignin test). Quinine dihydrochloride (Government Pharmaceutical Organisation of Thailand) $20 \mathrm{mg}$ of the salt $/ \mathrm{kg}$ (equivalent to $16.7 \mathrm{mg}$ of base $/ \mathrm{kg}$ ) as a single dose was injected deep into the anterior thigh. Further doses of $10 \mathrm{mg}$ salt $/ \mathrm{kg}$ were given eight hourly into alternate thighs. Patients were asked about pain at the site of injection and other side effects at 15 minute intervals for one hour and then hourly until the second dose. Pulse and blood pressure were measured every 15 minutes for one hour, half hourly for two hours, and then hourly. An electrocardiogram was recorded before and one hour after the first dose. Injection sites were examined daily until the patients left hospital. Blood samples for measurement of plasma quinine concentrations were taken through an indwelling intravenous Teflon catheter at 5,15 , and 30 minutes, and $1,1 \frac{1}{2}, 2,3,4,5,6,7$, and 8 hours after the loading dose. Further samples were taken before and one hour after each intramuscular dose and then daily, one hour after the first dose of the day.

Plasma was separated immediately and stored at $-25^{\circ} \mathrm{C}$ until assayed by the benzene extraction fluorescence method ${ }^{12}$ with an Aminco-Bowman spectrofluorimeter. Plasma quinine concentrations until eight hours after the loading dose were analysed by an iterative non-linear curve fitting program (Non-lin) and values for the absorption rate constant and absorption half life obtained from a one compartment model.

Eight patients, aged 23-48 (mean 34.6) years, were studied. Three had no history of an illness resembling malaria; the rest had had from one to over 10 previous attacks. All gave a history of fever lasting three to eight (mean $5 \cdot 3$ ) days, and temperatures on admission were $36 \cdot 8-39 \cdot 2$ (mean $38 \cdot 2)^{\circ} \mathrm{C}$. All were nauseated, and six had vomited before being admitted. All were conscious, but one was confused. Parasite counts on admission were

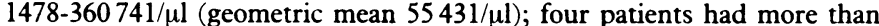
$4 \%$ parasitaemia. Other laboratory results (mean (SD)) were: packed cell volume $0.39(0.06)$, white cell count $5.3(2 \cdot 0) \times 10^{\circ} / 1$, blood urea nitrogen concentration $7 \cdot 8(3 \cdot 1) \mathrm{mmol} / 1(21 \cdot 4(8 \cdot 5) \mathrm{mg} / 100 \mathrm{ml})$, serum creatinine 120 (39) $\mu \mathrm{mol} / 1(1.4(0.4) \mathrm{mg} / 100 \mathrm{ml})$, albumin $33(5) \mathrm{g} / \mathrm{l}$, total bilirubin 28.7 $(14.0) \mu \mathrm{mol} / \mathrm{l}(1 \cdot 6(0.8) \mathrm{mg} / 100 \mathrm{ml})$, and direct bilirubin $10 \cdot 2(10 \cdot 0) \mu \mathrm{mol} / \mathrm{l}$ $(0.6(0 \cdot 6) \mathrm{mg} / 100 \mathrm{ml})$.

\section{Results}

All patients responded well; fever clearance time was 60 (SD 23) $\mathrm{h}$ and parasite clearance time $53(22) \mathrm{h}$.

Plasma quinine concentration-After the loading dose the median time to the peak quinine concentration of $11.9(1.6) \mathrm{mg} / 1(34.4(5.0) \mathrm{mmol} / \mathrm{l})$ was five hours (range four to eight), and six of the eight patients had plasma quinine concentrations greater than $10.0 \mathrm{mg} / 1(31.3 \mathrm{mmol} / \mathrm{l})$ by four hours. There was no lag phase and no overshoot in any patient (table). Plasma quinine concentrations rose further after intramuscular maintenance doses, then declined with clinical improvement and the switch to oral treatment (figure). 
Quinine concentrations and absorption kinetics after intramuscular injection

\begin{tabular}{|c|c|c|c|c|c|c|c|c|c|c|c|}
\hline $\begin{array}{c}\text { Case } \\
\text { No }\end{array}$ & Sex & $\begin{array}{c}\text { Weight } \\
\text { (kg) }\end{array}$ & $\begin{array}{l}\text { Height } \\
(\mathrm{cm})\end{array}$ & $\begin{array}{c}\text { First } \\
\text { dose } \\
\text { mg base })\end{array}$ & $\begin{array}{l}\text { Time to } \\
\text { first peak } \\
\text { (h) }\end{array}$ & $\begin{array}{c}\text { First peak } \\
\text { concentration } \\
(\text { mg l) }\end{array}$ & $\begin{array}{l}\text { Absorption } \\
\text { half life } \\
\text { (h) }\end{array}$ & $\begin{array}{l}\text { Absorption } \\
\text { constant } \\
(\text { h })\end{array}$ & $\begin{array}{l}\text { Time to maximum } \\
\text { concentration } \\
(\mathrm{h})\end{array}$ & 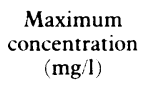 & $\begin{array}{l}\text { Lowest trough } \\
\text { in first } 48 \mathrm{~h} \\
(\mathrm{mg} / \mathrm{l})\end{array}$ \\
\hline 1 & $M$ & 47 & 145 & 940 & 4 & $12 \cdot 9$ & $1 \cdot 41$ & 0.49 & 48 & $15 \cdot 1$ & $11 \cdot 6$ \\
\hline 2 & $M$ & 55 & 161 & 1100 & 6 & $11 \cdot 2$ & $0 \cdot 20$ & 3.45 & 25 & $14 \cdot 1$ & $10 \cdot 7$ \\
\hline 3 & $M$ & 83 & 167 & 1660 & 5 & $12 \cdot 1$ & 0.56 & 1.25 & 25 & $18 \cdot 1$ & $11 \cdot 2$ \\
\hline 4 & $M$ & 56 & 155 & 1120 & 5 & $12 \cdot 7$ & $1 \cdot 14$ & 0.61 & 25 & 16.9 & $11 \cdot 2$ \\
\hline 5 & $M$ & 41 & 162 & 820 & 4 & $10 \cdot 3$ & 0.31 & $2 \cdot 22$ & 17 & $12 \cdot 3$ & 8.9 \\
\hline 6 & $\mathrm{~F}$ & 50 & 169 & 1000 & 8 & $8 \cdot 4$ & $0 \cdot 24$ & $2 \cdot 86$ & 48 & $19 \cdot 7$ & $7 \cdot 7$ \\
\hline 7 & $M$ & 65 & 172 & 1300 & 7 & $9 \cdot 7$ & 0.87 & $0 \cdot 80$ & 48 & $17 \cdot 5$ & $9 \cdot 5$ \\
\hline 8 & $M$ & 50 & 170 & 1000 & 4 & $10 \cdot 3$ & 0.66 & 1.05 & 48 & 13.8 & $8 \cdot 6$ \\
\hline Mean & & 55.9 & 163 & 1118 & & $11 \cdot 0$ & 0.67 & 1.59 & & 15.9 & $9 \cdot 9$ \\
\hline SD & & 13.0 & 9 & 261 & & 1.6 & 0.44 & $1 \cdot 11$ & & 2.5 & $1 \cdot 4$ \\
\hline
\end{tabular}

Conversion: Traditional units to $S I-1 \mathrm{mg}$ anhydrous quinine base $\approx 3 \mathrm{mmol}$.

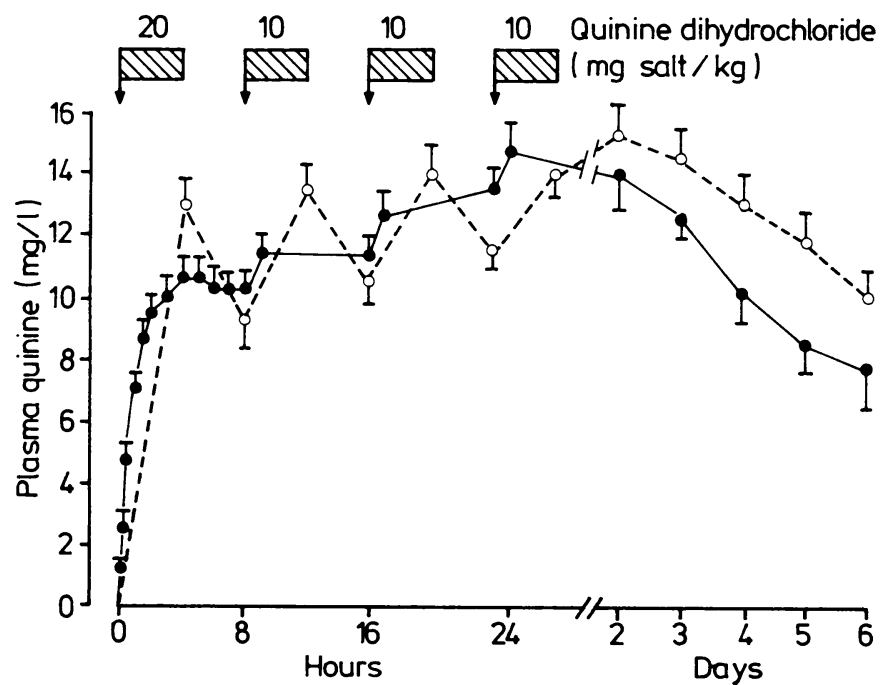

Plasma quinine concentrations after quinine loading dose given by intramuscular injection $(n=8)$ (continuous line) and by intravenous infusion $(n=15)^{13}$ (broken line). Values are means (SEM). In this study parenteral treatment was continued for 24-48 hours until patients could swallow tablets. Subsequent concentrations are values one hour after oral dosing.

Conversion: Traditional units to SI-1 $\mathrm{mg}$ anhydrous quinine base $\approx 3 \mathrm{mmol}$.

Quinine sulphate tablets, given in equivalent doses as soon as patients could swallow, were begun after four injections in six patients and after five injections in the two others. Comparison of plasma quinine concentrations in patients from the present study with those given an intravenous quinine loading dose ${ }^{13}$ showed a similar plasma concentration profile (figure). The mean plasma quinine concentration at the end of the intravenous loading dose was 12.9 (range $7 \cdot 5-17 \cdot 5) \mathrm{mg} / \mathrm{l}(40.3(23.4-54 \cdot 7) \mathrm{mmol} / \mathrm{l})$ with a trough concentration at eight hours of $9 \cdot 2(5 \cdot 3-12 \cdot 6) \mathrm{mg} / \mathrm{l}(28 \cdot 8(16 \cdot 6-39 \cdot 4) \mathrm{mmol} / \mathrm{l})$; the mean maximum plasma quinine concentration was $15 \cdot 6(12 \cdot 2-20 \cdot 8) \mathrm{mg} / 1$ $(48 \cdot 8(38 \cdot 1-65 \cdot 0) \mathrm{mmol} / \mathrm{l})$.

Toxicity-Despite a steady rise in plasma quinine concentration blood pressure and pulse rate did not change in any patient. No arrhythmias or serious conduction abnormalities were found. Pain at the injection site, which was mild to moderate, lasted between 15 and 60 minutes; no induration or abscess was detected in any patient.

All patients complained of deafness and tinnitus within an hour or two after receiving the loading dose. Three patients, all of whom had vomited before being admitted, did so again during the first 24 hours in hospital.

\section{Discussion}

An intramuscular loading dose of quinine proved a safe and effective method of beginning treatment in our eight adult patients with moderately severe falciparum malaria. Therapeutic plasma quinine concentrations were reached four to five hours after injection without entailing the expense and nursing supervision required for intravenous infusion. Plasma quinine concentrations were monitored closely; individual variation was small, concentrations rose steadily, and no dangerous peaks occurred. Further intramuscular injections at eight hourly intervals produced a plasma concentration profile closely resembling that obtained with intravenous infusions. For the first 72 hours of treatment plasma concentrations consistently exceeded the high minimum inhibitory concentration of quinine for $P$ falciparum prevalent in Thailand. Cinchonism was common, but there was a surprising lack of local pain and no cardiovascular toxicity. Parasite clearance times were comparable with those achieved by intravenous treatment. ${ }^{13}$

Intravenous infusion of quinine is the recommended treatment for severe falciparum malaria. ${ }^{1}$ In many rural clinics, however, intravenous fluid and administration sets are unobtainable and, anyway, infusions cannot be adequately supervised. Intravenous quinine injections are dangerous ${ }^{4}$ and rectal instillation too irritant. ${ }^{6}$ Patients unable to swallow tablets can be given intramuscular injections or have to be transferred to a hospital. Severe malaria can progress rapidly, and delays increase the risk of complications and death. ${ }^{14}$ The use of intramuscular antimalarials has not been properly evaluated, and clinical experience has created doubts about their safety. ${ }^{815}$

In 1926 Gage described the use of an intramuscular quinine loading dose and found it to be life saving in severe malaria. ${ }^{16}$ Other workers found this route useful in Asia and Africa. ${ }^{1720}$ Intramuscular quinine was used extensively in Java with few complications ${ }^{202}$ (R M Clark, personal communication), and this has also been the general experience in Papua New Guinea, where intramuscular quinine has been standard parenteral treatment for severe falciparum malaria for many years. ${ }^{21}$ Others, including reliable

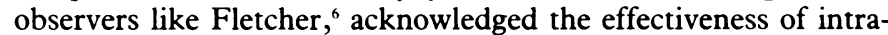
muscular quinine but had strong reservations about its use because of the local tissue damage it could cause.

Some of the local complications that occur after injection of quinine, such as tetanus, bacterial abscess, and septicaemia, are clearly attributable to unsterile technique,$^{22}$ while sciatic nerve palsy is avoidable if injections are correctly sited and the gluteal region is not used. The site chosen for injection is also an important determinant of drug absorption as well as toxicity. ${ }^{23}$ In Caucasians injections given into the buttock will often be deposited in fat rather than muscle, ${ }^{24}$ this being the most likely reason why absorption from this site is less reliable than that from the thigh or deltoid..$^{23}$ Even when correctly injected, however, many drugs may be $N$ incompletely absorbed when given intramuscularly, especially in N patients who are shocked. This could have serious implications during treatment of a potentially fatai infection, and several authors do not recommend intramuscular quinine for this reason. ${ }^{1025}$

There is convincing evidence that sterile quinine (and quinidine ${ }^{26}$ ) may cause muscle damage. European authors have recommended the use of galenic preparations, which minimise local tissue damage. ${ }^{27}$ Quinine hydrochloride with urethane as the solvent may be preferable to the dihydrochloride, which is acid $(\mathrm{pH}=3 \cdot 5)$. Careful attention to the technique of injection and use of neutral preparations should minimise the risk of serious injury after intramuscular quinine. In patients unable to swallow tablets the benefits outweigh the risks, but indiscriminate use of injectable antimalarials is to be deplored; the dangers of this practice were recognised 60 years ago. ${ }^{6}$ , 
Earlier studies of quinine concentrations after intramuscular injection were encouraging, ${ }^{11252 \times}$ although none of this work excluded the possibility of transient but toxic peak concentrations. Our results show that a loading dose results in therapeutic plasma concentrations within four hours of injection and that absorption is reliable in patients with moderately severe malaria without the risk of high peaks seen after intramuscular chloroquine (see accompanying paper, p 11). Further work is needed to assess the use of this route in severe, complicated malaria and in children. It is certainly not the ideal route for administration of quinine, but in the absence of the equipment or skills for intravenous infusion intramuscular quinine could be life saving; the risks have been exaggerated.

We are grateful to the director, Dr Sanga Boonbamrung, and staff of Paholpolpayuhasena Hospital, Kanchanaburi, for their cooperation; to Khun Nucharee Cholvilai and Kristin Headlam for secretarial help; and to Dr W H Wernsdorfer of the World Health Organisation, Geneva, for helpful discussion. This study is part of the Wellcome-Mahidol University, Oxford tropical medicine research programme financed by the Wellcome Trust of Great Britain.

\section{References}

1 World Health Organisation Scientific (iroup. Advances in malaria chemotherapy. WHO Tech Report Ser 1984; No 711 .

2 World Health Organisation. Severe and complicated malaria. Trans $R$ Soc Trop Med Hyg in

3 White NJ, Looareesuwan S, Warrell DA, Warrell MJ, Bunnag D, Harinasuta T. Quinine pharmacokinetics and toxicity in cerebral and uncomplicated falciparum malaria. Am $\mathcal{J}$ Med pharmacokinetics

4 White NJ, Chanthavanich P, Krishna S, Bunch C, Silamut K. Quinine disposition kinetics. Br $\mathrm{f}$ Clin Pharmacol 1983:16:399-404.

5 Marchiafava E, Bignami A. On summer-autumn malarial fevers. London: New Sydenham Society, 1894 .
6 Fletcher W'. Studies from the Institute for Medical Research, Kuala Lumpur, Federuted Malay States. London: John Bale, Sons and Danielsson, 1923:24-42.

7 Hall AP. The treatment of severe falciparum malaria. Trans $R$ Soc Trop Med Hyg 1977;71:367-78.

8 Thuriaux MD. Quinine by intravenous infusion for falciparum malaria. Br Med f 1982:285:1429. 9 Spencer HC, Strickland (TT. Malaria. In: Strickland GT, ed. Hunter's tropical medicine, 6th ed. Philadelphia: W B Saunders, 1984:546.

10 W'yler DJ. Malaria. In: Mandell GL, Douglas RG, Bennett JE, eds. Principles and practice of infectious diseases. 2nd ed. New York: Wiley, 1985:1514-22.

11 Shann F, Stace J, Fdstein M. Pharmacokinetics of quinine in children. Pediatrics 1985;106 506-10.

12 Cramer ( , Isaksson B. Quantitative determination of quinidine in plasma. Scand 7 Clin Lab Invest 1963:15:553-6

13 White NJ, Looareesuwan S, Warrell DA, Warrell MJ, Bunnag D, Harinasuta T. Quinine loading dose in cerebral malaria. Am f Trop. Med Hyg 1983;32:1-5.

14 W'arrell DA, Looareesuwan S, W'arrell MJ, et al. Dexamethasone proves deleterious in cerebral malaria. A double blind trial in 100 comatose patients. N Engl f Med 1982;306:313-9.

15 Trigg PL, Wernsdorfer WH, Sheth UK, Onorr E. Intramuscular chloroyuine in children. Lancet 1984:ii: 288 .

16 Gage A. Algid malaria. Therapeutic (jazette 1926:50:77-81.

17 Chopra RN, Rov AC. On the concentration of quinine in the blocod after intravenous and intramuscular injections. Indian Medical (jazetle 1934;69:560-6.

18 Murphy RA. Quinine in the therapeutics of malaria. Indian Medical Gazette 1934;69-566-7.

19 Le Van Hung. Paludisme en grossesse à Saigon. Recue du Paludisme et de Medecine Tropical Van Hung. P. Pac

20 Collomb $\mathrm{H}$, Rey M. Lacces pernicieux palustre en zone d'endemie. Medecine D'A frique Noir 1967;14:29-31

20a (iramberg KPCA. De behandeling van malaria. Ned Tijdschr (jeneeskd 1985;129:611.

21 Government of Papua New Guinea. Standard treatment for common illnesses of children in Papu Nez: Guinea. Port Moresby: Government of Papua New Guinea, 1984.

22 Guyer B, Candy D. Injectable antimalarial therapy in tropical Africa: iatrogenic disease an wasted medical resources. Trans $R$ Soc Trop. Med Hyg 1979;73:230-2

23 Greenblatt DJ, Koch-Weser J. Intramuscular injection of drugs. N Engl f. Med 1976;295:542-6.

24 Cockshott WP. Thompson GI, Howlett LJ, Seelev E.T. Intramuscular or intralipomatou njections? N Engl f. Med 1982:307:356-8.

25 Hall AP. Hanchalay S, Doherstrn EB. Bumnetphund S. Quinine dosage and serum levels in Galciparum malaria Anual Progress Report of the SFATO Reseurch Lahoraton 1974-5:241-50. falcipart DJ, Pfeifer HJ. Och HR a lhare (crence

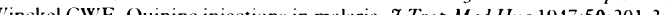

28 Chongsuphajaisiddhi, $T$, Dauruag V, Patchavakessakul V, Kittivattanaku V. Dulvasakdi $B$ Ridthimat $\mathbb{W}$. Treatment of falciparum malaria with intramuscular quinine in a rural area of Thailand. Southeast Asian f Trop Med Hyg 1983:14:220-2.

Accepled l Mav 1986

\title{
Divided dose intramuscular regimen and single dose subcutaneous regimen for chloroquine: plasma concentrations and toxicity in patients with malaria
}

\author{
R E PHILLIPS, D A WARRELL, G EDWARDS, YAMUNA GALAGEDERA, \\ R D G THEAKSTON, D T D J ABEYSEKERA, P DISSANAYAKA
}

\begin{abstract}
Adults with malaria in Sri Lanka were treated with parenteral chloroquine diphosphate, either $2.5 \mathrm{mg}$ base/ $\mathrm{kg}$ intramuscularly at $0,1,12,13,24$, and 25 hours or $5 \mathrm{mg}$ base $/ \mathrm{kg}$ subcutaneously at
\end{abstract}

Nuffield Department of Clinical Medicine, University of Oxford

R E PHILLIPS, FRACP, Wellcome lecturer

D A WARRELL, DM, FRCP, clinical reader

Department of Parasitology, Liverpool School of Tropical Medicine, and Department of Pharmacology and Therapeutics, University of Liverpool G EDWARDS, PHD, lecturer

Anuradhapura General Hospital, Anuradhapura, Sri Lanka

YAMUNA GALAGEDERA, MB, BS, house officer

D T D J ABEYSEKERA, MRCP, consultant

P DISSANAYAKA, MRCP, consultant

Department of Tropical Medicine, Liverpool School of Tropical Medicine R D G THEAKSTON, PHD, senior lecturer

Correspondence to: Dr D A Warrell, Faculty of Tropical Medicine, Mahidol University, Bangkok 10400, Thailand.
0, 12, and 24 hours. Both regimens were completed with oral chloroquine phosphate, $5 \mathrm{mg}$ base $/ \mathrm{kg}$, at 36 and 48 hours. Mean peak chloroquine concentrations in the first 12 hours, which were 0.5 (range $0.3-0.6) \mathrm{mg} / 1(1.4(0.9-1.7) \mathrm{mmol} / \mathrm{l})$ with the intramuscular regimen and $0.3(0.2-0.4) \mathrm{mg} / 1(1.0(0.7-1.3) \mathrm{mmol} / \mathrm{l})$ with the subcutaneous regimen $(p<0.05)$, were reached in median times of $90(65-90)$ minutes and 30 (30-60) minutes respectively $(p<0.05)$ after the start of treatment. The mean area under the plasma concentration curve for the first $\mathbf{1 2}$ hours was $1.4(0.9-2.1) \mathrm{mg} / 1 . \mathrm{h}(4.5(2.8-6.4) \mathrm{mmol} / 1 . h)$ after intramuscular administration and $1.8(0.8-2 \cdot 3) \mathrm{mg} / \mathrm{l} . \mathrm{h}(5 \cdot 7(2 \cdot 7-7 \cdot 2) \mathrm{mmol} / \mathrm{l} . \mathrm{h})$ after subcutaneous administration $(p>0 \cdot 1)$. Mean maximum plasma concentrations were higher after intramuscular administration $(0.6(0.4-0.8) \mathrm{mg} / 1(1.7(1.3-2.5) \mathrm{mmol} / \mathrm{l}))$ than after subcutaneous administration $(0.4(0.4-0.5) \mathrm{mg} / 1 \quad(1.3 \quad(1.3-$ $1.5) \mathrm{mmol} / \mathrm{l}))(\mathrm{p}<0.05)$, but both regimens produced satisfactory plasma profiles. Chloroquine resistance was found in the only case of Plasmodium falciparum malaria.

Chloroquine is absorbed rapidly after divided dose intramuscular injection and single dose subcutaneous injection and does not cause hypotension or neurotoxicity in adults. Similar regimens should be evaluated in children before the parenteral use of this drug is abandoned. 